\title{
Chemometric Analysis of UV Characteristic Profile and Infrared Fingerprint Variations of Coffea arabica Green Beans under Different Space Management Treatments
}

\author{
Amélia E. Terrile, ${ }^{a, b}$ Gustavo G. Marcheafave, ${ }^{a}$ Guilherme S. Oliveira, ${ }^{a}$ \\ Miroslava Rakocevic, ${ }^{c}$ Roy E. Bruns ${ }^{d}$ and Ieda S. Scarminio ${ }^{*, a}$ \\ ${ }^{a}$ Laboratório de Quimiometria em Ciências Naturais, Departamento de Química, \\ Universidade Estadual de Londrina, CP 6001, 86051-990 Londrina-PR, Brazil \\ ${ }^{b}$ Departamento de Química, Universidade Tecnológica Federal do Paraná, Campus Londrina, \\ Avenida dos Pioneiros 3131, 86036-370 Londrina-PR, Brazil \\ ${ }^{c}$ Embrapa Informática Agropecuária, Campus da UNICAMP, Barão Geraldo, \\ CP 6041, 13083-886 Campinas-SP, Brazil \\ 'Instituto de Química, Universidade Estadual de Campinas, CP 6154, \\ 13083-970 Campinas-SP, Brazil
}

\begin{abstract}
Ultraviolet characteristic profiles and infrared spectroscopic (FTIR) fingerprints of green bean extracts of Coffea arabica L., cv. IAPAR 59, cultivated in two planting patterns, rectangular and square, and at two different densities, 10,000 and 6,000 plants ha ${ }^{-1}$, identified as $R_{10}, R_{6}, S_{10}$, and $S_{6}$ were analyzed with principal component and hierarchical cluster analyses. A simplex centroid design for four solvents (ethanol, acetone, dichloromethane, hexane) was used for sample extraction. The largest chlorogenic acid (CGA) contents were found at the lower planting density. The dichloromethane extracts of the $S_{10}$ treatment showed the highest levels of unsaponifiable lipids (cafestol and kahweol). The $\mathrm{R}_{6}$ treatment showed a slightly higher content of cafestol and kahweol. Cluster analysis of FTIR fingerprints confirmed that the CGA and caffeine levels differentiate the spatial arrangements. The FTIR fingerprints suggest that green beans from $\mathrm{S}_{6}$ and $\mathrm{R}_{10}$ were richer in lipids and the other two treatments had more sugars and proteins.
\end{abstract}

Keywords: plant architecture, arabica coffee, UV-Vis spectroscopy, FTIR spectroscopy, chemometric analysis

\section{Introduction}

The chemical compositions of Coffea arabica green beans consist of hundreds of different metabolites. The production of these metabolites is influenced by coffee culture managements, soil, climate conditions (temperature and rainfall, solar radiation), plant architecture and harvesting and post-harvesting procedures such as drying, storage and roasting. ${ }^{1-5}$ Chlorogenic acids (CGA) are related to sensory characteristics of brewed coffee drink, especially the astringent, acidic and bitter flavors. Significant and positive correlations have been found between the temperature and the formations of 3-caffeoylquinic (3-CQA) and 4-caffeoylquinic acid (4-CQA), whereas

\footnotetext{
*e-mail: ieda@qui.uel.br
}

a negative correlations occurs for 5-caffeoylquinic acid (5-CQA), which corresponds to 70-80\% of CGA in coffee. ${ }^{6}$ Altitude has significant and positive correlation with CGA concentration. However, no discussion was provided to prove whether this relationship owes to ground and climate conditions or temperature gradient. ${ }^{7}$

Coffee tree architecture is characterized by continuous growth and dimorphic axes-orthotropic and plagiotropic. An orthotropic axis follows an opposite-decussate phyllotaxy. At each node, it forms two plagiotropic axes of the $2^{\text {nd }}$ order, even though sometimes, no branch or just one develops. In Coffea arabica L. (arabica coffee), the plagiotropic axes develop from the $2^{\text {nd }}$ to the $5^{\text {th }}$ orders; the highest branching orders appearing after three to four years. ${ }^{8}$

During the last twenty years high planting densities have been used to increase coffee production, by raising 
the planting densities from the traditional 700-800 per hectare to 5,000-10,000. The study of variations in densities and planting patterns in coffee culture studies has involved biological and agronomical analyses, such as fruit production ${ }^{9}$ as well as ecophysiological explanations about light access, water stress ${ }^{10-12}$ and mineral absorption impacts. ${ }^{13,14}$

Information about chemical modifications in coffee leaves and beans when subjected to different plant managements can be obtained by metabolomic analysis. It consists on sampling, sample preparation, use of instrumental analytical techniques, processing and interpretation of data. ${ }^{15}$ It produces metabolic profiles or fingerprints, providing information about changes in the plant under different growing conditions, soil, climate and other factors. ${ }^{16}$ During sample preparation, the extraction process is a key step because it aims isolating the metabolites of the vegetable matrix. The choice of extraction solvent can be made by appropriate statistical mixture designs. ${ }^{17}$

UV-Vis and infrared spectroscopic analytical techniques have been used in the identification and quantification of metabolome constituents in coffee. Sample preparation is relatively simple and the reagents and equipment are not very expensive. UV-Vis spectroscopy has been applied to caffeine quantification, ${ }^{18-21}$ simultaneous determination of methylxanthines, ${ }^{22}$ determination of chlorogenic acids and their antioxidant activities ${ }^{23-25}$ as well as coffee classification. ${ }^{26}$ Fourier transform infrared (FTIR) is an important method for identifying chemical constituents and elucidating their structures and has been considered the best and simplest technique to identify and characterize biomolecules. ${ }^{27}$ This technique has been used in coffee samples to estimate methylxanthine amounts in tea and coffee, ${ }^{28}$ determine the effects of roasting conditions; ${ }^{29}$ discriminate between defective and non-defective roasted coffees $^{30}$ and between roasted coffees and their adulterants. ${ }^{31}$

The spectra subjected to fingerprint analyses contain variance information that can be extracted using a wide variety of chemometric methods. ${ }^{32-34}$ Multivariate analysis methods, such as principal component analysis (PCA) ${ }^{35}$ and cluster analysis (CA), ${ }^{36}$ allow dimensionality reduction of multivariate data and the extraction of essential results from large data sets. These analytical techniques can be associated with adequate methods of multivariate analysis for extracting information about the influence of the space management treatments, such as density and planting patterns, in the production of metabolites in Coffea arabica L. beans. The aim of this work was to investigate ultraviolet (UV) and infrared spectral (FTIR) changes in green bean extracts of Coffea arabica cv. IAPAR 59 grown in two planting patterns and at two planting densities. The varying effects of different mixture design solvents on extraction from coffee samples increase the chances of observing the most important spectral changes.

\section{Experimental}

\section{Site conditions and coffee plant management}

Coffee plants (Coffea arabica L., cv. IAPAR 59) were cultivated in two planting patterns: rectangular $(\mathrm{R})$ and square (S) at two densities: 10,000 and 6,000 plants ha ${ }^{-1}$ in experimental fields of the Agronomical Institute of Paraná, in the city of Londrina, Paraná State $\left(23^{\circ} 18^{\prime} \mathrm{S}\right.$ and $\left.51^{\circ} 17^{\prime} \mathrm{W}\right)$, Brazil. The distance between plants was $1 \mathrm{~m} \times 1 \mathrm{~m}\left(\mathrm{~S}_{10}\right)$, $3 \mathrm{~m} \times 0.33 \mathrm{~m}\left(\mathrm{R}_{10}\right), 1.29 \mathrm{~m} \times 1.29 \mathrm{~m}\left(\mathrm{~S}_{6}\right)$ and $3 \mathrm{~m} \times 0.55 \mathrm{~m}$ $\left(\mathrm{R}_{6}\right)$. Visually mature berries were collected in June of 2010, defining the first production year after very low pruning (carried out in 2008).

\section{Reagents and sample preparation}

The solvents used for extract preparation were ethanol from Exodo (Hortolândia, Brazil), acetone from Fmaia (Cotia, Brazil), dichloromethane and hexane both from Anidrol (Diadema, Brazil). Malic and citric acids were purchased from Synth (Diadema, Brazil). All were of analytical grade quality.

The coffee beans were dried in the sun on a concrete yard until reaching $12.5 \%$ moisture content. After drying, the beans were cleaned of bark and parchment and all visible defects removed. The beans were frozen with liquid $\mathrm{N}_{2}$ and were ground to a $0.5 \mathrm{~mm}$ particle size (mill Perten 3600 ). Posteriorly, they were sieved through a Granutest ABNT sieve $25,071 \mathrm{~mm}$, Tyler 24 . The processed samples were packaged into plastic bags and sealed under vacuum in sealant Selovac model 120 BO. The samples were stored in a freezer/cooler Electrolux model $160 \mathrm{M}$, at $-18{ }^{\circ} \mathrm{C}$.

\section{Simplex centroid design}

A simplex centroid design for four components was used for obtaining the sample extracts from each treatment. Ethanol, acetone, dichloromethane, hexane and their binary, ternary and quaternary mixtures were investigated (Table 1). Because the coffee bioactive compounds have different polarities, the choice of solvents for extraction was based on this property. Previous studies developed in our laboratory have shown the efficiency of these solvents and their mixtures in the extraction of coffee compounds..$^{21,33,34}$

The extractions were performed with $2.50 \mathrm{~g}$ of crushed beans and $60 \mathrm{~mL}$ of extracting solvent in ultrasonic bath 
(Ultracleaner 1400 Unique), for $120 \mathrm{~min}$ and maintained at $15 \pm 2{ }^{\circ} \mathrm{C}$ with ice. After filtration, the filtrate was collected and the extraction cycle was repeated with the residue. The process was considered exhaustive when a complete overlap occurred between the UV-Vis spectra of two consecutive extractions. The spectrophotometer used was a Thermo Scientific Evolution 60. The solvent was removed in a rotary evaporator (Fisatom model 801) and then the extract was lyophilized at $-81.5 \pm 0.1{ }^{\circ} \mathrm{C}$ and $20 \pm$ 2 mTorr (Lyophilizer SP Scientific Virtis).

Table 1. Simplex centroid design for four components: ethanol (e), acetone (a), dichloromethane (d) and hexane (h)

\begin{tabular}{|c|c|c|c|c|}
\hline \multirow{2}{*}{ Extract $^{\mathrm{a}}$} & \multicolumn{4}{|c|}{ Solvent } \\
\hline & Ethanol (e) & Acetone (a) & Dichloromethane (d) & Hexane (h) \\
\hline $\mathrm{e}$ & 1 & 0 & 0 & 0 \\
\hline $\mathrm{a}$ & 0 & 1 & 0 & 0 \\
\hline $\mathrm{d}$ & 0 & 0 & 1 & 0 \\
\hline $\mathrm{h}$ & 0 & 0 & 0 & 1 \\
\hline ea & $1 / 2$ & $1 / 2$ & 0 & 0 \\
\hline de & $1 / 2$ & 0 & $1 / 2$ & 0 \\
\hline eh & $1 / 2$ & 0 & 0 & $1 / 2$ \\
\hline da & 0 & $1 / 2$ & $1 / 2$ & 0 \\
\hline ah & 0 & $1 / 2$ & 0 & $1 / 2$ \\
\hline $\mathrm{dh}$ & 0 & 0 & $1 / 2$ & $1 / 2$ \\
\hline dea & $1 / 3$ & $1 / 3$ & $1 / 3$ & 0 \\
\hline deh & $1 / 3$ & 0 & $1 / 3$ & $1 / 3$ \\
\hline eah & $1 / 3$ & $1 / 3$ & 0 & $1 / 3$ \\
\hline dah & 0 & $1 / 3$ & $1 / 3$ & $1 / 3$ \\
\hline deah1 & $1 / 4$ & $1 / 4$ & $1 / 4$ & $1 / 4$ \\
\hline deah2 & $1 / 4$ & $1 / 4$ & $1 / 4$ & $1 / 4$ \\
\hline deah3 & $1 / 4$ & $1 / 4$ & $1 / 4$ & $1 / 4$ \\
\hline deah4 & $1 / 4$ & $1 / 4$ & $1 / 4$ & $1 / 4$ \\
\hline deah5 & $1 / 4$ & $1 / 4$ & $1 / 4$ & $1 / 4$ \\
\hline deah6 & $1 / 4$ & $1 / 4$ & $1 / 4$ & $1 / 4$ \\
\hline
\end{tabular}

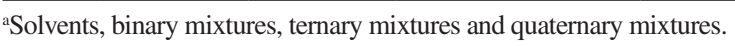

\section{Analysis by UV-Vis spectroscopy}

UV-Vis spectra were obtained with $50 \mathrm{mg}$ of each extract dissolved in $20 \mathrm{~mL}$ of respective extractor solvent. The mixture was placed in an ultrasound bath for $20 \mathrm{~min}$. The spectra were obtained in the 190-800 nm range with the UV-Visible Thermo Scientific model Evolution 60S, using quartz cuvettes with a $1 \mathrm{~cm}$ optical path length.

\section{Analysis by infrared spectroscopy (FTIR)}

Spectra in the infrared region $\left(4000-675 \mathrm{~cm}^{-1}\right)$ of crude extracts were obtained with a Thermo Scientific Nicolet iS10 FT-IR spectrometer, using the ATR (attenuated total reflectance) accessory with a Ge window. The measurement was done in the transmittance mode, with 64 scans and $4 \mathrm{~cm}^{-1}$ resolution.

Data processing

Architectural data extraction from the Multiscale Tree Graphs (MTG's) was performed using AMAPstudio-Xplo software. ${ }^{37}$ Special attention was paid to berry distribution along the orthotropic trunk and axes of second order. The extracted number of berries per rank/metamer/axes were used to generate berry distributions.

The Statistica 7.0 software was used in the statistical data analyses for the UV-Vis and infrared spectra. The spectra and loading graphs were plotted using the Origin Pro 8 software.

\section{Results and Discussion}

Architecture of orthotropic axis and average berry distribution over the coffee plants

The plant height did not differ between the planting patterns (PPs) and densities, but the metamer number at the orthotropic axes was higher in rectangular PPs than in square ones (Figure 1). In rectangular PP and higher density, the competition between plants in the row promoted apical dominance more than in square PP and lower density.

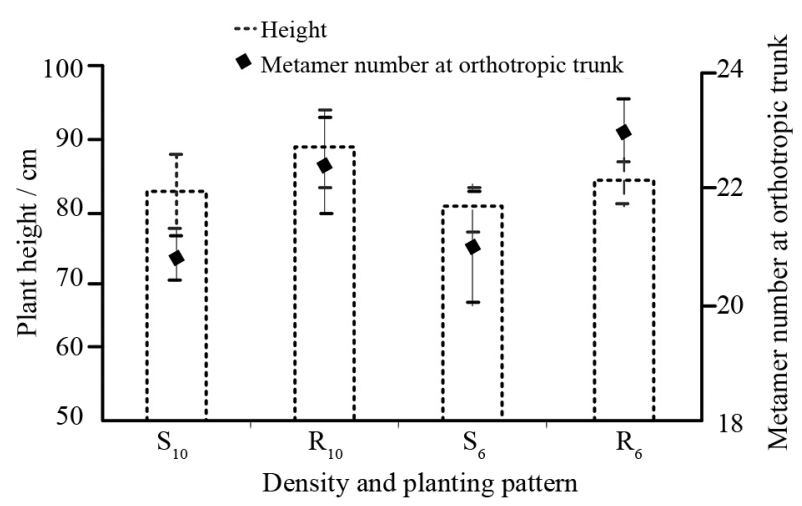

Figure 1. Mean and standard error values for height and metamer number of the orthotropic trunk. Plants were cultivated under two planting patterns (S-square and R-rectangular) and densities (6 and 10 thousand plants ha ${ }^{-1}$ ). In some cases, the two deviations overlap.

\section{UV-Vis characteristic profile analysis}

The absorption spectra data were subjected to PCA, 
in order to visualize the natural clusters in metabolites from green coffee beans caused by planting densities and patterns. Spectral data (absorbance) were arranged in a matrix of 601 rows and 80 columns, where each row represents a wavelength variable and each column a sample extract (20 simplex design mixtures for four spatial arrangements), to calculate the principal components and cluster analysis. The first three principal components explain $89.40 \%$ of the total variance of the data.

Although the scores of $2^{\text {nd }}$ and $3^{\text {rd }}$ principal components (PC) account for only $30.79 \%$ of the total data variance, they provided the important chemical feed-back (Figure 2). The graphical separations of the extraction points were due to the different sample properties and their solvent interactions in the varying solvent media. The separation of extracts along the $2^{\text {nd }}$ factor (PC2) showed two clusters: on the negative side are the extract points from pure ethanol (e), dichloromethane (d) and hexane (h), the dh, de, eh binary mixtures and the deh ternary mixture. Their UV spectra represent the characteristic profile of the bioactive compounds of coffee (methylxanthines, chlorogenic acids and pentacyclic alcohols). The extracts obtained with acetone (a) and their mixtures with the other solvents are grouped on the positive side of PC2. Their profile indicate the presence of acids and phenolic compounds. Extracts of acetone and hexane:acetone $(1: 1 \mathrm{v} / \mathrm{v})$ were separated from other solvents in factor 3 (PC3). Some metabolites were identified by their absorption spectra.

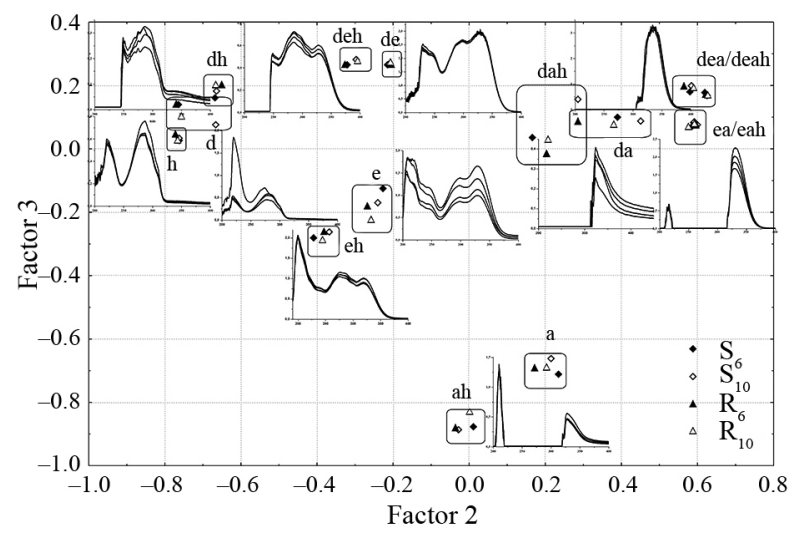

Figure 2. PC2 $\times$ PC3 score plots of UV-Vis characteristic profile of crude extracts of Coffea arabica, cv. IAPAR 59 green beans. Plants were cultivated under two planting patterns (S-square and R-rectangular) and densities ( 6 and 10 thousand plants ha ${ }^{-1}$ ).

The spectra of the ethanol extracts have two peaks: the first at $217 \mathrm{~nm}$ with a shoulder at $245 \mathrm{~nm}$ and the second peak at $329 \mathrm{~nm}$ with shoulder at $298 \mathrm{~nm}$. The minimum was at $264 \mathrm{~nm}$ (Figure 3a). The two peaks with their shoulders correspond to HOMO $\rightarrow$ LUMO (highest occupied molecular orbital to the lowest unoccupied molecular orbital) electronic transitions. These spectra are typical of chlorogenic acids (CGA) and have been characterized and determined in coffee beans by UV-Vis spectroscopy. ${ }^{38}$ The low planting density treatments $\left(\mathrm{S}_{6}\right.$ and $\left.\mathrm{R}_{6}\right)$ showed higher CGA contents than the treatments with high planting density $\left(\mathrm{S}_{10}\right.$ and $\left.\mathrm{R}_{10}\right)$. The larger space available for each plant at 6,000 plants $a^{-1}$ relative to that at 10,000 plants ha $^{-1}$ allows an increase in solar radiation incidence. UV radiation generates free radicals that cause cell damage under this condition, and plants produce antioxidant compounds as defense mechanisms, ${ }^{39}$ therefore the CGA
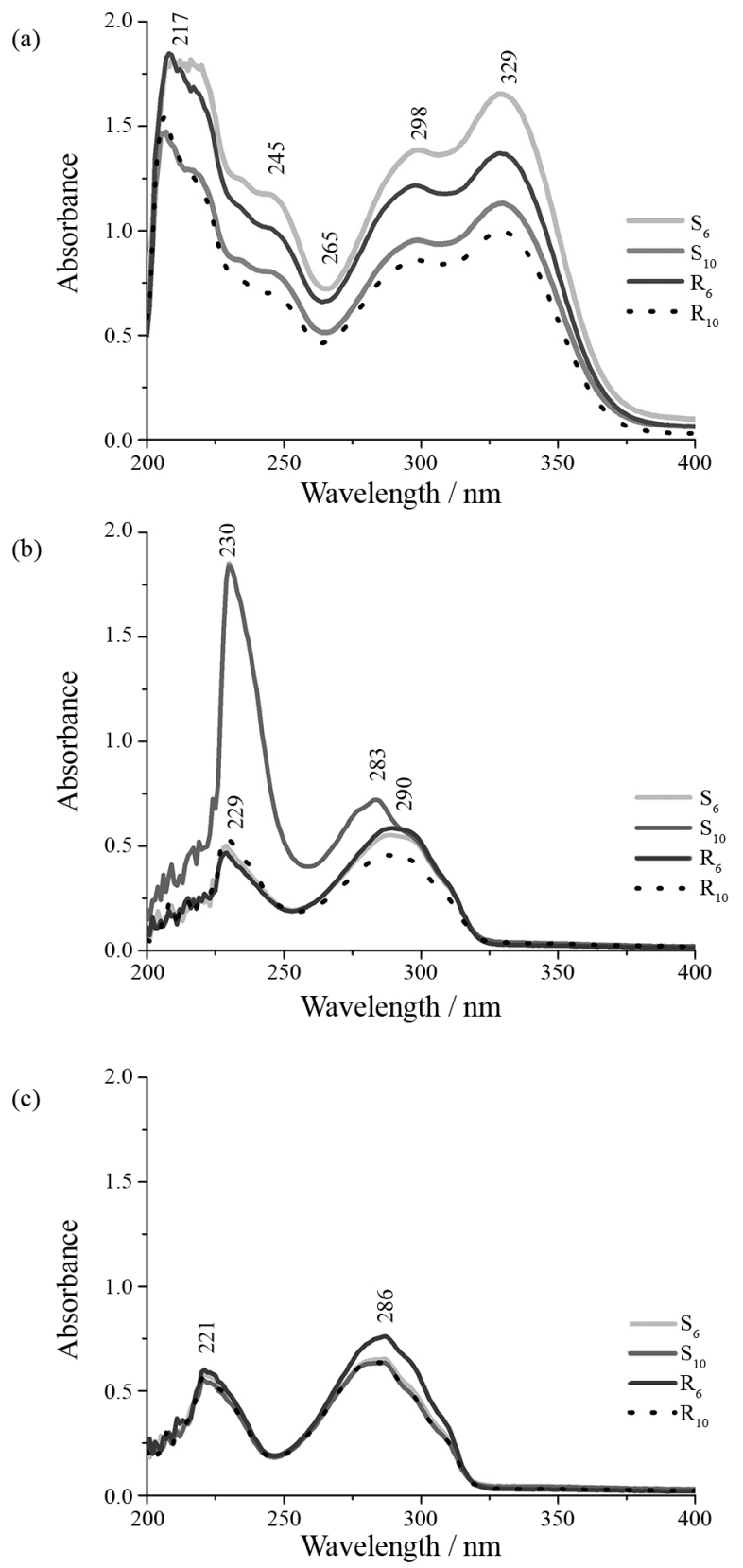

Figure 3. Spectra of (a) ethanol; (b) dichloromethane; (c) hexane extracts of green beans of Coffea arabica, cv. IAPAR 59. Plants were cultivated under two planting patterns (S-square and R-rectangular) and two densities (6 and 10 thousand plants ha ${ }^{-1}$ ). 
level increases. Furthermore, this result indicates that the chlorogenic acid content is related to plant height (Figure 1).

The dichloromethane and hexane extract spectra show the same profile with two peaks: $229-230 \mathrm{~nm}$ and 283-290 $\mathrm{nm}$ for the dichloromethane extracts (Figure 3b) and 221 and $286 \mathrm{~nm}$, for the hexane extracts (Figure 3c). These peaks are characteristic for unsaponifiable lipids of coffee, cafestol and kahweol. Values for these pentacyclic alcohols were reported at $225 \mathrm{~nm}$ for cafestol and $288 \mathrm{~nm}$, for kahweol. ${ }^{40}$ The $S_{10}$ treatment showed higher contents of cafestol and kahweol in the dichloromethane extract. In the hexane extract, the $\mathrm{R}_{6}$ treatment showed a slightly higher kahweol content compared with other treatments. Methylxanthines (caffeine, theobromine and theophylline) also absorb in this spectral region. Studies on caffeine in tea leaves showed that this methylxanthine absorbs between 244 and $300 \mathrm{~nm}$ when the solvent extractor was dichloromethane. In this case, the wavelength $\left(\lambda_{\max }\right)$ was $276 \mathrm{~nm} .{ }^{19}$ In water extraction, the methylxanthines showed $\lambda_{\max }$ between 270 and $280 \mathrm{~nm} \cdot{ }^{41}$ Consequently, the spectra of these alkaloids could be masked by the kahweol spectrum. In the $\mathrm{PC} 2 \times \mathrm{PC} 3$ score plot of Figure 2, the dichloromethane and hexane extracts are grouped very closely, at negative PC2 scores. This confirms that their compositions are similar.

Pairs of extract spectra prepared in $\mathrm{a} / \mathrm{ah}$, ea/eah, da/dah and dea/deah exhibited the same spectral profile (Figure 2), indicating the same metabolite class but with higher intensity than those prepared in acetone. The extract spectra obtained with pure acetone and their mixtures with ethanol and/or hexane exhibited two peaks. The peak at $215 \mathrm{~nm}$ is characteristic of citric or malic acid, according to information obtained in our laboratory, having patterns of these acids dissolved in their respective solvent under the same conditions. The peak at $330 \mathrm{~nm}$ was not identified.

The principal component results were confirmed by cluster analysis (CA) as shown in the dendrogram of Figure 4. The treatments were identified with the numbers $1\left(\mathrm{~S}_{6}\right), 2\left(\mathrm{~S}_{10}\right), 3\left(\mathrm{R}_{6}\right)$ and $4\left(R_{10}\right)$. When the dendrogram is examined at the point 7.0 (linkage distance), six groups are found. Each group consists of spectra having some similarities. Group I only contains extract spectra obtained with the dichloromethane:ethanol mixture. The profile spectra indicated that this mixture extracted different metabolites than those extracted by their pure solvents. Group II contains extracts obtained from the dea and deah mixtures. Therefore, these mixtures extracted the same types of metabolites having an unidentified peak at $330 \mathrm{~nm}$. Group III corresponds to the spectra of the ea and eah extracts. The $215 \mathrm{~nm}$ peak differentiates between the spectra Groups II and III. The extract spectra obtained with ethanol and the ethanol:hexane mixture constitute Group IV, with chlorogenic acid profiles (Figure 3a). Group V is formed only by the $S_{10}$ dichloromethane extract spectrum. This indicates differences in pentacyclic alcohol (cafestol and kahweol) contents when compared with the other three treatments. The spectra of $\mathrm{S}_{6}, \mathrm{R}_{10}$ and $\mathrm{R}_{6}$ dichloromethane extracts are grouped together with the

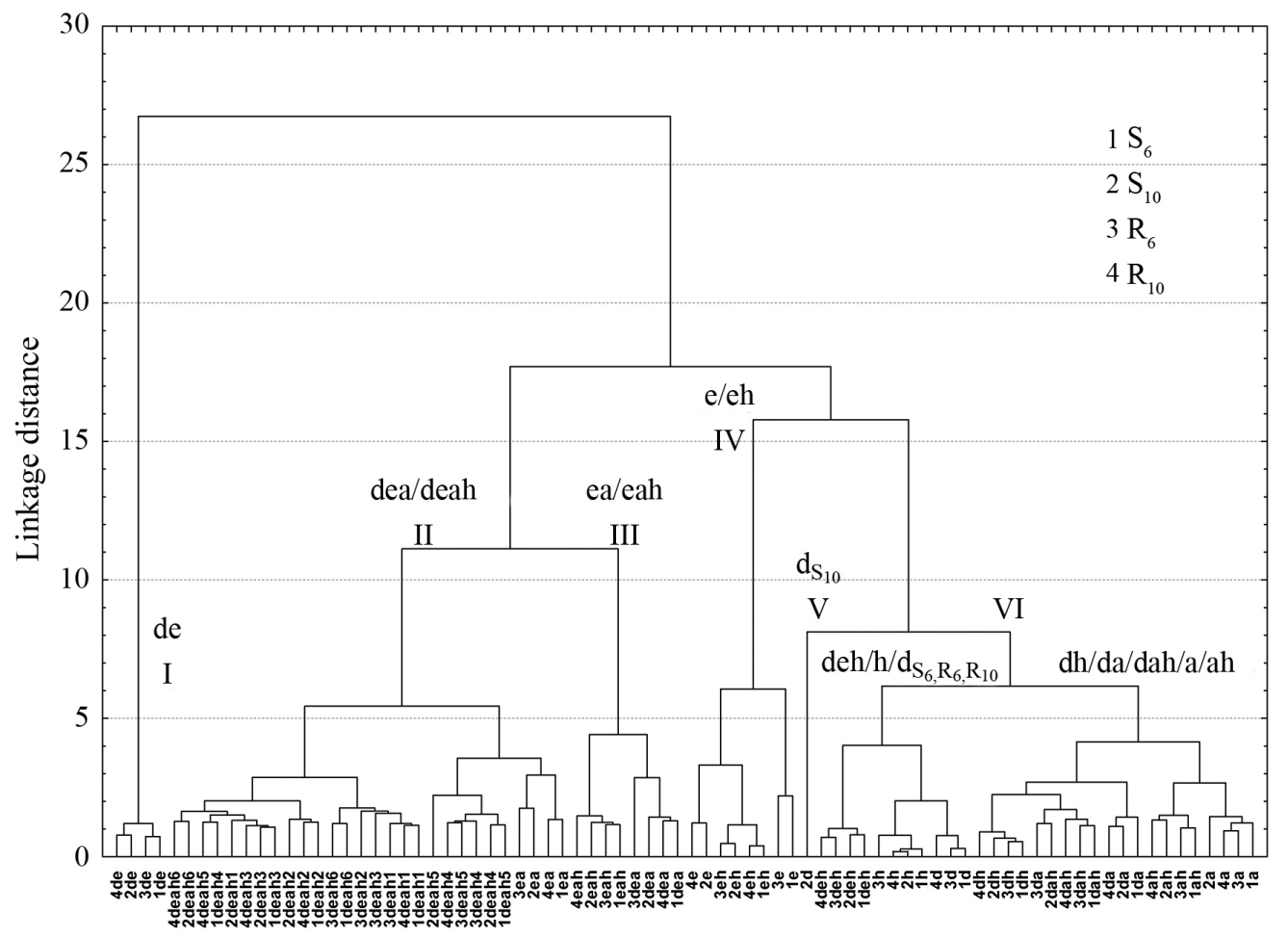

Figure 4. Dendrogram of the UV spectra of extracts obtained from green grains of $C$. arabica, cv. IAPAR 59. Plants were cultivated under two planting patterns (S-square and R-rectangular) and two densities (6 and 10 thousand plants ha-1). The treatments were identified with the numbers $1\left(\mathrm{~S}_{6}\right), 2\left(\mathrm{~S}_{10}\right), 3\left(\mathrm{R}_{6}\right)$ and $4\left(\mathrm{R}_{10}\right)$. 
extract spectra obtained with $\mathrm{h}$, dh, deh, a, ah, and dah, forming Group VI. Figures $3 b$ and $3 \mathrm{c}$ show similar profiles for the $S_{6}, R_{10}$ and $\mathrm{R}_{6}$ dichloromethane and hexane extract spectra. Together these extracts form a subgroup of Group VI.

\section{FTIR fingerprint analysis}

PCA was also conducted on the complete FTIR spectra. The matrix was composed of 80 samples (extracts) and 1678 variables. The first two principal components explained $99.03 \%$ of the total data variance. The PC1 $\times$ PC 2 score plot shows two groups separated on PC2 (Figure 5a), appearing very different from those at Figure 2, where extracts were grouped according to the extractor solvent. The spectral points lay on one of two almost straight lines indicating two major components (Figure 5a). Overlaying points with similar extracts fall at the intersection whereas the more divergent spectra occur at the two extreme limits. The pure hexane and dichloromethane solvents and binary and ternary mixtures containing acetone and dichloromethane (Group I) have positive values of PC2.
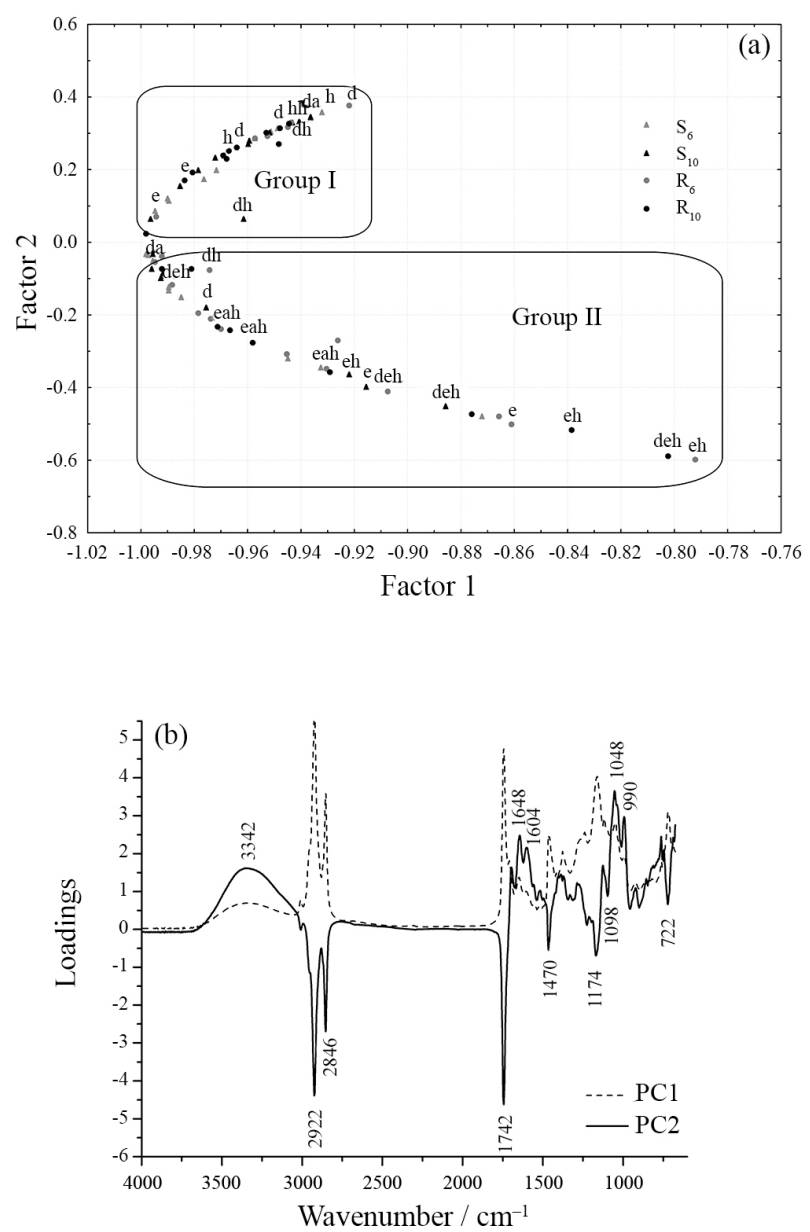

Figure 5. (a) PC1 $\times$ PC2 score plot; (b) their loading plot for the FTIR extract spectra obtained from green beans of C. arabica, cv. IAPAR 59. Plants were cultivated under two planting patterns ( $\mathrm{S}$-square and R-rectangular) and two densities ( 6 and 10 thousand plants ha ${ }^{-1}$ ).
The extracts of binary or ternary mixtures containing ethanol and hexane fall at negative PC2 values (Group II). In order to view the points of interest more easily, some symbols identifying the extracts were eliminated.

Figure $5 \mathrm{~b}$ shows the $\mathrm{PC} 1$ and $\mathrm{PC} 2$ loading plots. Along $\mathrm{PC} 2$, large positive loadings are found at $3342,1648,1604$, 1048 and $990 \mathrm{~cm}^{-1}$ and correspond to the crude extracts of Group I (binary or ternary mixtures containing acetone and dichloromethane). The samples of Group II have large negative loadings for frequency values at 2922, 2846, 1742, $1470,1174,1098$ and $722 \mathrm{~cm}^{-1}$. The bands in $1500-2000 \mathrm{~cm}^{-1}$ range were related to $\mathrm{C}=\mathrm{C}$ and $\mathrm{C}=\mathrm{O}$ stretching modes, but depending on the type of $\mathrm{C}=\mathrm{O}$ bond bands can vary within the $1650-1830 \mathrm{~cm}^{-1}$ region. $\mathrm{C}=\mathrm{N}$ stretching also occurs in this region. ${ }^{42}$ In Group I, bands observed at 3342 (N-H stretching) and $1648 \mathrm{~cm}^{-1}$, probably correspond to caffeine. The dichloromethane solvent belongs to this group and has been used to decaffeinate and isolate caffeine from aqueous coffee extracts. ${ }^{43}$ In Group II, the band at $1742 \mathrm{~cm}^{-1}$ characterizes the stretching vibration of the carbonyl group of methyl ester and the region between 1179 and $1166 \mathrm{~cm}^{-1}$ is assigned to $\mathrm{C}-\mathrm{O}$ stretching of esters. ${ }^{44}$ The band at $1174 \mathrm{~cm}^{-1}$ is characteristic of the stretching vibration of the $\mathrm{C}-\mathrm{O}$ bond of higher esters. ${ }^{45,46}$ The hexane extract belongs to Group II and this solvent is frequently used in the lipid extraction. ${ }^{47}$ The bands at 2918 and $2861 \mathrm{~cm}^{-1}$ are attributed respectively to the asymmetric and symmetric stretching vibrations of $\mathrm{sp}^{3}$ hybridized $\mathrm{C}-\mathrm{H}$ bonds. The band at $1464 \mathrm{~cm}^{-1}$ corresponds to the symmetrical angular deformation of methylene groups. ${ }^{42}$ These groups are present in the fatty acids studied in coffee..$^{48}$

The spectra of the points of Groups I and II (Figure 5a) were plotted to examine their behavior. The dichloromethane extract $R_{6}\left(R_{6} d\right)$ was chosen to represent the extreme of Group I. The ethanol:hexane extract of $R_{6}\left(R_{6}\right.$ eh) and the dichloromethane:ethanol:hexane extract of $R_{10}\left(R_{10}\right.$ deh) represented the extreme of the Group II (Figure 5a). Similarly, their corresponding spectra of the square arrangement $S_{10}$ deh, $\mathrm{S}_{6}$ eh and $\mathrm{S}_{6}$ d extracts were plotted to search for possible changes in metabolite production owing to planting pattern. Their FTIR fingerprint are presented in Figure 6.

The $\mathrm{R}_{10}$ deh, $\mathrm{R}_{6}$ eh and $\mathrm{S}_{10}$ deh spectra (Figures 6a, 6b and $6 \mathrm{~d}$ ) have different characteristics from those provided by the loading plot for Group II (Figure 5b). These spectra have a broad band around $3333 \mathrm{~cm}^{-1}$ and sharper ones at 1644 , 1600,1050 and $993 \mathrm{~cm}^{-1}$. These bands are coincident with the Group I peaks in the loading plot. Other bands were observed for these extracts at 1747 (fatty acid esters) and 1704 (organic acid) $\mathrm{cm}^{-1} .{ }^{49}$ The region with bands at $1452,1380,1260,1128$ and $1059 \mathrm{~cm}^{-1}$ can be attributed to chlorogenic acids. ${ }^{50}$ The spectral bands of beans collected from rectangular planting patterns $\left(R_{10}\right.$ deh and $R_{6}$ eh) were more intense than those of 

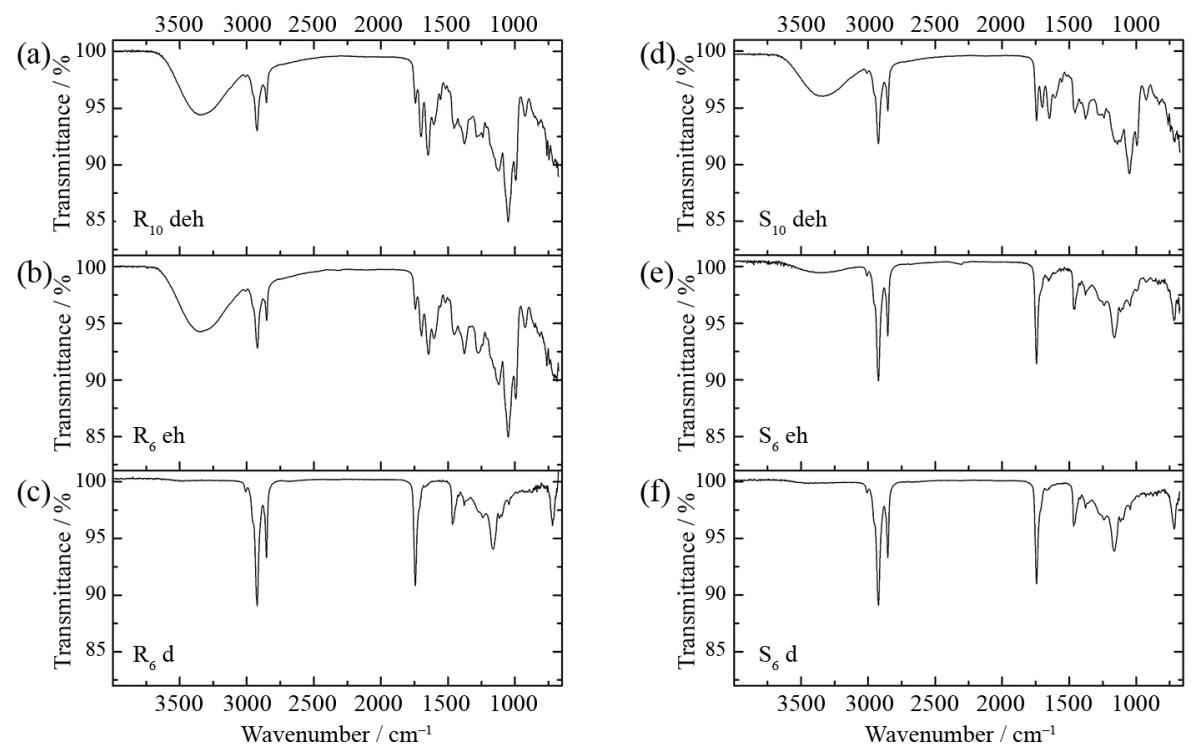

Figure 6. FTIR spectra of (a) $\mathrm{R}_{10} \mathrm{deh}$; (b) $\mathrm{R}_{6} \mathrm{eh}$; (c) $\mathrm{R}_{6} \mathrm{~d}$; (d) $\mathrm{S}_{10} \mathrm{deh}$; (e) $\mathrm{S}_{6}$ eh; (f) $\mathrm{S}_{6}$ d obtained from green bean extracts of $C$. arabica, cv. IAPAR 59. Plants were cultivated under two planting patterns ( $\mathrm{S}$-square and $\mathrm{R}$-rectangular) and two densities ( 6 and 10 thousand plants ha $\left.\mathrm{a}^{-1}\right)$.

bean extracts of the $S_{10}$ spectra $\left(S_{10}\right.$ deh). The $R_{6} d$ and $S_{6} d$ extract spectra (Figures $6 \mathrm{c}$ and $6 \mathrm{f}$ ) exhibit the same profile but they do not have the characteristic bands of Group I: 3342, $1648,1604,1048$ and $990 \mathrm{~cm}^{-1}$ as shown on the positive values of the loading plot (Figure 5b). These spectra present bands at 2920, 2865, 1735, 1459, 1165, 1095 and $721 \mathrm{~cm}^{-1}$, the same as those of Group II. Other bands characterize these extracts: 3010 (=C-H stretching), 1380 (C-H bending of $\mathrm{CH}_{3}$ group), and $721 \mathrm{~cm}^{-1}$ (rocking motion of $\left(\mathrm{CH}_{2}\right)_{\mathrm{n}}$ when $\left.\mathrm{n} \geq 4\right)^{42}$ and the region between 1300 and 1000 (C-O stretching). ${ }^{44}$ This information indicates the possible presence of fatty acid esters in the $\mathrm{R}_{6}$ and $\mathrm{S}_{6}$ dichloromethane grain extracts, meaning that more available soil space for plants leads to the formation of more fatty acids.

The $\mathrm{S}_{6}$ eh spectrum (Figure 6e) has a similar profile to the $R_{6} d$ and $S_{6} d$ spectra (Figures $6 c$ and $6 f$ ) and these extracts were placed in Group I (Figure 5a). The ethanol:hexane extracts of the other three treatments $\left(\mathrm{R}_{6}, \mathrm{R}_{10}\right.$ and $\left.\mathrm{S}_{10}\right)$ are in Group II. This suggests that the $\mathrm{S}_{6}$ metabolites extracted by the ethanol:hexane mixture are different from those of the $S_{10}$, $\mathrm{R}_{6}$ and $\mathrm{R}_{10}$ metabolites, due to the distribution over the coffee plant architecture (Figure 1).

The results of PCA were confirmed by CA. A linkage distance of 0.6 discriminates three groups (Figure 7). Group I (extracts of binary or ternary mixtures of acetone and dichloromethane) (Figure 5a) is located on the right of the dendrogram whereas Group II extracts of binary or ternary mixtures of ethanol and hexane are located on the left while the third group is not clearly characterized. Group III contained extracts obtained with the quaternary mixtures of solvents and those obtained with the ethanol:dichloromethane mixture. Figure 7 also shows that space management treatments are separated by the pure ethanol and dichloromethane solvents, indicating that levels of chlorogenic acids and cafestol/kahweol or caffeine could discriminate these treatments. These results can be compared with those obtained for the UV-Vis spectra of ethanol and dichloromethane extracts (Figures $3 a$ and $3 b$ ). The spectra of the ethanol extracts showed a CGA profile with the $\mathrm{S}_{6}$ treatment having the highest contents of these acids (Figure 3a). In the CA of infrared fingerprint, the $\mathrm{S}_{6}$ ethanol extract is isolated from the others $\left(S_{10} e, R_{6}\right.$ e and $\left.R_{10} e\right)$ in Group III (Figure 7). In the UV-Vis characteristic profile (Figure 3b), the $S_{10}$ treatment exhibits the highest content of cafestol and kahweol and it appears separated from the others in Group III of the infrared dendrogram (Figure 7).

The four FTIR spectra of bean extracts obtained with the ethanol:dichloromethane mixture showed similar spectral profiles (Figure 8a). The bands at $3331(\mathrm{~N}-\mathrm{H})$ and 1695 , 1648 and $1604 \mathrm{~cm}^{-1}$ can be attributed to $\mathrm{C}=\mathrm{C}$ and $\mathrm{C}=\mathrm{N}$ stretching. These groups are present in caffeine. The bands at $1742 \mathrm{~cm}^{-1}$ (C=O stretching), 2841 and $2920 \mathrm{~cm}^{-1}(\mathrm{C}-\mathrm{H}$ stretching of $\mathrm{CH}_{2}$ and $\mathrm{CH}_{3}$ groups) and $1165 \mathrm{~cm}^{-1}(\mathrm{C}-\mathrm{O}$ stretching) can be assigned to triacylglycerols. ${ }^{44}$ The weak band at $3009 \mathrm{~cm}^{-1}$ can be attributed to $\mathrm{C}-\mathrm{H}$ stretching in $=\mathrm{C}-\mathrm{H} .{ }^{51}$ This indicates the presence of unsaturated fatty acids.

The FTIR spectra of ethanol extracts for $S_{10}$ and $R_{6}$ showed bands in various regions that were different from those of the $S_{6}$ and $R_{10}$ spectra (Figure $8 b$ ). Only spectra from first two have a broad band in the $3100-3600 \mathrm{~cm}^{-1}$ region attributed to the presence of compounds with $\mathrm{O}-\mathrm{H}$ and $\mathrm{N}-\mathrm{H}$ groups. ${ }^{46}$ The band at $1742 \mathrm{~cm}^{-1}$ corresponds to the ester group of triacylglycerols and is less intense than in the ethanolic spectra of $\mathrm{R}_{10}$ and $\mathrm{S}_{6}$. The region between 


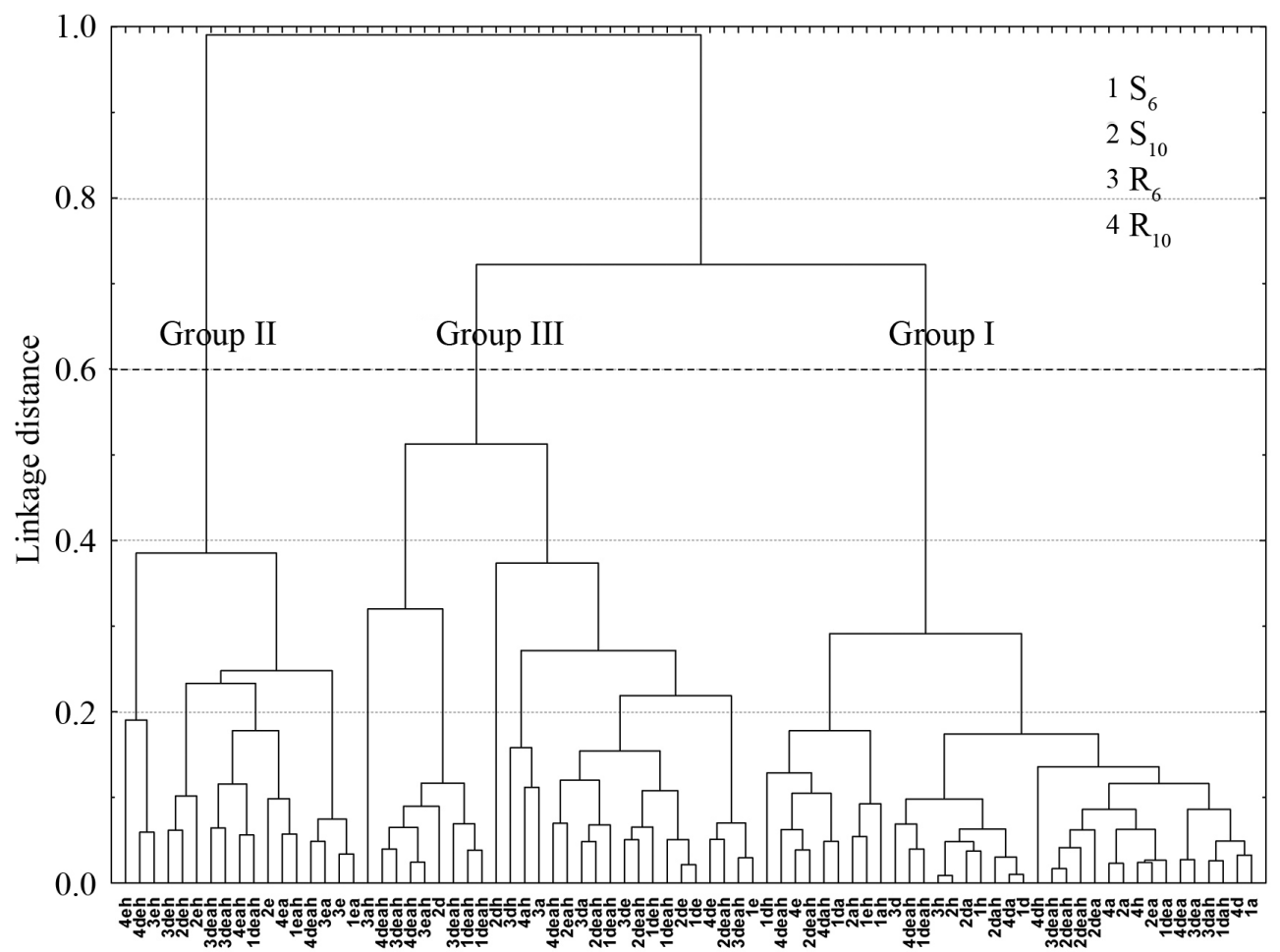

Figure 7. Dendrogram of the FTIR spectra of extracts obtained from green grains of $C$. arabica, cv. IAPAR 59. Plants were cultivated under two planting patterns (S-square and R-rectangular) and two densities (6 and 10 thousand plants ha $\left.{ }^{-1}\right)$. The treatments were identified with the numbers $1\left(\mathrm{~S}_{6}\right), 2\left(\mathrm{~S}_{10}\right), 3\left(\mathrm{R}_{6}\right)$ and $4\left(\mathrm{R}_{10}\right)$.
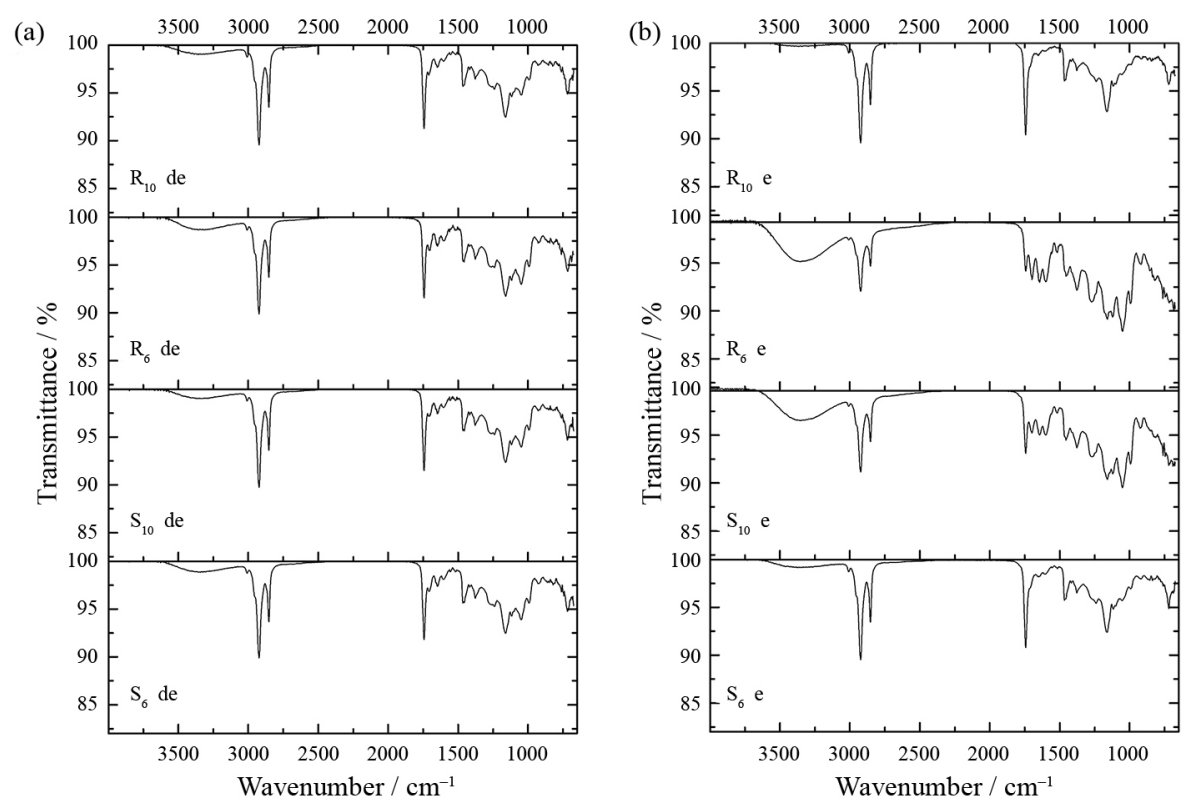

Figure 8. FTIR spectra of (a) ethanol:dichloromethane; (b) ethanol extracts obtained from green beans of $C$. arabica, cv. IAPAR 59. Plants were cultivated under two planting patterns (S-square and R-rectangular) and two densities (6 and 10 thousand plants ha $\left.{ }^{-1}\right)$.

1700 and $1500 \mathrm{~cm}^{-1}$ can be assigned to the peptide bond $(\mathrm{C}-\mathrm{NH})$ absorption of the protein backbone. ${ }^{45}$ Moreover, they present several intense bands in the region between 1325 and $950 \mathrm{~cm}^{-1}$. This region can be associated with carbohydrates. ${ }^{45}$ The $\mathrm{S}_{6}$ and $\mathrm{R}_{10}$ spectra have characteristic triacylglicerols bands: 1742 (intense), the $3000-2800 \mathrm{~cm}^{1}$ region corresponding to $\mathrm{C}-\mathrm{H}$ stretching, 1463 and $1379 \mathrm{~cm}^{1}$ $\left(\mathrm{CH}_{2}\right.$ and $\mathrm{CH}_{3}$ scissoring $)$ and 1121 and $720 \mathrm{~cm}^{-1}\left(\mathrm{CH}_{3}\right.$ and $\mathrm{CH}_{2}$ wagging) ${ }^{44}$ This suggests that these space management treatments may have higher triacylglycerol contents than $\mathrm{S}_{10}$ and $\mathrm{R}_{6}$. This triacylglycerol metabolomic fingerprint could be related to the berry distribution (Figure 1). 


\section{Conclusions}

The PCA of the UV-Vis spectra showed that characteristic profile differences were assigned mainly to ethanol extracts that exhibit a characteristic chlorogenic acid profile. The highest CGA content was found for the lower planting density treatments $\left(\mathrm{S}_{6}\right.$ and $\left.\mathrm{R}_{6}\right)$. The dichloromethane and hexane spectra showed cafestol and kahweol peaks. The $\mathrm{S}_{10}$ treatment showed higher contents of these unsaponifiable lipids in the dichloromethane extract. The hexane extract of the $\mathrm{R}_{6}$ treatment showed a slightly higher content of these pentacyclic alcohols relative to those of the other treatments. Based in this analysis, bioactive coffee compounds can be extracted using the pure solvents. The cluster analysis of FTIR fingerprints confirmed that the levels of chlorogenic acids and caffeine differentiated these treatments. The FTIR spectra analysis suggests that $\mathrm{S}_{6}$ and $\mathrm{R}_{10}$ present more lipid contents whereas $\mathrm{S}_{10}$ and $\mathrm{R}_{6}$ treatments have more content of sugars and proteins.

\section{Acknowledgments}

This work was support by CNPq, Fundação Araucária and Consórcio Brasileiro de Pesquisa e Desenvolvimento de Cafés, Brazilian granting agencies.

\section{References}

1. da Matta, F. M.; Ramalho, J. D. C.; Braz. J. Plant Physiol. 2006, 18,55 .

2. Thierry, J.; Laffargue, A.; Descroix, F.; Doulbeau, S.; Bertrand, B.; Kochko, A.; Dussert, S.; Food Chem. 2010, 118, 693.

3. Gonzalez-Rios, O.; Suarez-Quiroz, M. L.; Boulanger, R.; Barel, M.; Guyot, B.; Guiraud, J. P.; Schorr-Galindo, S.; J. Food Compos. Anal. 2007, 20, 289.

4. Selmar, D.; Bytof, G.; Knopp, S. E.; Ann. Bot. 2008, 101, 31.

5. Hečimović, I.; Belščak-Cvitanović, A.; Horžić, D.; Komes, D.; Food Chem. 2011, 129, 991.

6. Jöet, T.; Laffarge, A.; Descroix, F.; Doulbeau, S.; Bertrand, B.; Kochko, A.; Dussert, S.; Food Chem. 2010, 118, 693.

7. Bertrand, B.; Boulanger, R.; Dussert, S.; Ribeyre, F.; Berthiot, L.; Descroix, F.; Joët, T.; Food Chem. 2012, 135, 2575.

8. Rakocevic, M.; Androcioli-Filho, A.; Coffee Sci. 2010, 5, 154.

9. Paulo, E. M.; Furlani Jr., E.; Sci. Agric. 2010, 67, 720.

10. Santana, M. S.; Oliveira, C. A. S.; Quadros, M.; Eng. Agric. 2004, 24, 644 .

11. Melke, A.; Fetene, M.; Theor. Exp. Plant Physiol. 2014, 26, 225.

12. Nascimento, L. M.; Sphar, C. R.; Sandri, D.; Coffee Sci. 2014, 9, 354 .

13. Valadares, S. V.; Neves, J. C. L.; Novais, R. F.; Rosa, G. N. G.
P.; Martinez, H. E. P.; Venegas, V. H. A.; R. Bras. Ci. Solo 2014, $38,905$.

14. Prezotti, L. C.; da Rocha, A. C.; Bragantia 2004, 63, 239.

15. Dunn, W. B.; Ellis, D. I.; TrAC, Trends Anal. Chem. 2005, 24 , 285.

16. Villas-Bôas, S. G.; Gombert, A. K.; Biotecnologia Cienc. Desenvolv. 2006, 9, 58.

17. Soares, P. K.; Bruns, R. E.; Scarmínio, I. S.; J. Sep. Sci. 2007, 30,3302

18. Belay, A.; Ture, K.; Redi, M.; Asfaw, A.; Food Chem. 2008, 108,310 .

19. Atomssa, T.; Gholap, A. V.; Afr. J. Pure Appl. Chem. 2011, 5, 1.

20. Dobrinas, S.; Soceanu, A.; Popescu, V.; Stanciu, G.; Smalberger, S.; St. Cerc. St. CICBIA 2013, 14, 71.

21. Delaroza, F.; Rakocevic, M.; Malta, G. B.; Bruns, R. E.; Scarminio, I. S.; J. Braz. Chem. Soc. 2014, 25, 1929.

22. Martínez, L. L.; López-de-Alba, P. L.; Campos, R. G.; Rodríguez, L. M. L.; Anal. Chim. Acta 2003, 493, 83.

23. Atoui, A. K.; Mansouri, A.; Boskou, G.; Kefalas, P.; Food Chem. 2005, 89, 27.

24. Parras, P.; Martínez-Tomé, M.; Jiménez, A. M.; Murcia, M. A.; Food Chem. 2007, 102, 582.

25. Vignoli, J. A.; Bassoli, D. G.; Benassi, M. T.; Food Chem. 2011, 124,863 .

26. Souto, U. T. C. P.; Pontes, M. J. C.; Silva, E. C.; Galvão, R. K. H.; Araújo, M. C. U.; Sanches, F. A. C.; Cunha, F. A. S.; Oliveira, M. S. R.; Food Chem. 2010, 119, 368.

27. Kumar, J. K.; Prasad, A. G. D.; Drug Invent. Today 2012, 4, 616.

28. Paradkar, M. M.; Irudayara, J.; J. Food Sci. 2002, 67, 2507.

29. Lyman, D. J.; Benck, R.; Dell, S.; Merle, S.; Murray-Wijelath, J.; J. Agric. Food Chem. 2013, 51, 3268.

30. Craig, A. P.; França, A. S.; Oliveira, L. S.; Food Sci. Technol. 2012, 47, 505.

31. Reis, N.; França, A. S.; Oliveira, L. S.; Food Sci. Technol. 2013, 50,715 .

32. de Souza, R. M. N.; Benassi, M. T.; J. Braz. Chem. Soc. 2012, 23,1347 .

33. Moreira, I.; Scarminio, I. S.; Talanta 2013, 107, 416.

34. Moreira, I.; Scheel, G. L.; Hatumura, P. H.; Scarminio, I. S.; Quim. Nova 2014, 37, 39.

35. Marques, J. M.; Marques, M. A. M.; Rev. FAE Curitiba 2005, $8,93$.

36. Miller, J. N.; Miller, J. C.; Statistics and Chemometrics for Analytical Chemistry, $6^{\text {th }}$ ed.; Pearson: Gosport, UK, 2010.

37. Griffon, S.; de Coligny, F.; Ecol. Modell. 2014, $290,3$.

38. Belay, A.; Gholap, A. V.; Afr. J. Pure Appl. Chem. 2009, 3, 234.

39. Heck, C. I.; Mejia, E. G.; J. Food Sci. 2007, 72, 138.

40. Dias, R. C. E.; de Faria, A. F.; Mercadante, A. Z.; Bragagnolo, N.; Benassi, M. T.; J. Braz. Chem. Soc. 2013, 24, 492. 
41. Khanchi, A. R.; Mahani, M. K.; Hajihosseini, M.; Maragheh, M. G.; Chaloosi, M.; Bani, F.; Food Chem. 2007, 103, 1062.

42. Pavia, D. L.; Lampman, G. M.; Kriz, G. S.; Introduction of Spectroscopy: A Guide for Students of Organic Chemistry, $2^{\text {th }}$ ed.; Saunders College Publishing: Orlando, USA, 1996, pp. 511.

43. Toci, A.; Farah, A.; Trugo, L. C.; Quim. Nova 2006, $29,965$.

44. Chapman, D.; J. Am. Oil Chem. Soc. 1965, 42, 353.

45. Dufour, E. In Infrared Spectroscopy for Food Quality, Analysis and Control; Sun, D.-W., ed.; Academic Press: USA, 2009, pp. 448 .

46. Mistry, B. D.; Handbook of Spectroscopy Data: ChemistryUV, IR, PMR, CNMR and Mass Spectroscopy; Oxford Book Company: Jaipur, India, 2009, pp. 242.
47. Brum, A. A. S.; Arruda, L. F.; Regitano-D’Arce, M. A. B.; Quim. Nova 2009, 32, 849.

48. Nikolova-Damyanova, B.; Velikova, R.; Jham, G. N.; Food Res. Int. 1998, 31, 479.

49. Dimitrić-Marković, J. M.; Mioć, U. B.; Baranac, J. M.; Nedić, Z. P.; J. Serb. Chem. Soc. 2001, 66, 451.

50. Segneanu, A. E.; Grozescu, I.; Sfirloaga, P.; Dig. J. Nanomater. Bios. 2013, 8, 1423.

51. Schulz, H.; Baranska, M.; Vib. Spectrosc. 2007, 43, 13.

Submitted: October 20, 2015

Published online: January 27, 2016

FAPESP has sponsored the publication of this article. 